Case Study

\title{
Effect of a combined thoracic and backward lifting exercise on the thoracic kyphosis angle and intercostal muscle pain
}

\author{
WON-GYU YOO ${ }^{1)}$ \\ 1) Department of Physical Therapy, College of Biomedical Science and Engineering, Inje University: \\ 607 Obangdong, Gimhae, Gyeongsangnam-do 621-749, Republic of Korea
}

\begin{abstract}
Purpose] This study developed a combined thoracic and backward lifting exercise for thoracic kyphosis angle and intercostal muscle pain. [Subject and Methods] The subject was a 41-year-old man who complained of upper thoracic and intercostal pain. He performed the combined thoracic and backward lifting exercise for 15 days. [Results] The initial VAS score for the intercostal area was 4/10. The VAS score decreased to $1 / 10$ after the thoracic exercise combined with backward lifting. The initial thoracic kyphosis angle was $38^{\circ}$ and it decreased to $32^{\circ}$ after the exercise period. [Conclusion] Therefore, backward lifting and thoracic extension is a good posture for activating the different layers of muscle that are attached to the ribs. The kyphosis angle is also reduced by providing sufficient resistance during the thoracic exercise.

Key words: Backward lifting, Intercostal pain, Scapulocostal pain
\end{abstract}

(This article was submitted Apr. 28, 2017, and was accepted May 29, 2017)

\section{INTRODUCTION}

The intercostal muscles have different layers that are attached to the ribs and help to stabilize the chest with movement and hold the ribs together and in place ${ }^{1}$. The intercostal muscles are skeletal muscles morphologically and functionally, and help to move the ribs upward and outward, increasing the anteroposterior diameter of the thoracic cavity ${ }^{2}$. The intercostal muscles can be strained by twisting the upper body beyond its limits ${ }^{3,4)}$. This can also "overstretch" the muscles and put pressure on the ribcage. Intercostal muscle sprain is a self-limiting medical condition, although measures can be used to reduce the pain and inflammation ${ }^{1,3,4)}$. Thoracic kyphosis can accelerate degenerative processes and contribute to thoracic dysfunction and thoracic pain ${ }^{1)}$. A stretching and strengthening rehabilitation program for thoracic pain reduces the symptoms and pain and improves function ${ }^{1)}$. In the chest, musculoskeletal changes can occur in the ribs and sternum ${ }^{2}$. This study developed a combined thoracic and backward lifting exercise for thoracic kyphosis angle and intercostal muscle pain.

\section{SUBJECT AND METHODS}

The subject was a 41-year-old man who complained of upper thoracic and intercostal pain, and had a forward-head posture. The purpose and methods of the study were explained to the participant before his inclusion, and he gave informed consent. The study adhered to the principles of the Declaration of Helsinki.

He had complained of continuous upper thoracic and intercostal pain for 2 months, but had not undergone any specific treatment for this condition. The pain consisted of mechanical upper thoracic pain without radiating pain. He felt sudden intercostal pain after twisting his trunk. The visual analogue scale (VAS) score of this intercostal pain was 4. A Dual Inclinometer (Acumar; Lafayette Instrument Company, Lafayette, IN, USA) was used to measure the thoracic kyphosis angle. 
The feet of the inclinometer were placed over the spinal processes of the 1 st and 2 nd thoracic vertebrae and 12 th thoracic and 1 st lumbar vertebrae, as determined by palpation. Measurements were made with the subject in a relaxed standing posture. The initial thoracic kyphosis angle was $38^{\circ}$. The thoracic exercise consisted of thoracic extension with the breath held for a few seconds, after breathing in slowly and opening his lungs as much as possible. During the thoracic extension exercise, he clasped both arms behind his back with the elbows flexed, gently arching his back and lifting a $10 \mathrm{~kg}$ weight backward. He performed 10 sets of 10 repetitions of the thoracic extension exercises daily for 15 days.

\section{RESULTS}

The initial VAS score for the intercostal area was 4/10. The VAS score decreased to $1 / 10$ after the thoracic exercise combined with backward lifting. The initial thoracic kyphosis angle was $38^{\circ}$ and it decreased to $32^{\circ}$ after the exercise period.

\section{DISCUSSION}

There are many causes of chest pain. Pain may originate from structures within the thorax, such as the heart, lungs, or esophagus. However, musculoskeletal causes of chest pain must be considered. Intercostal pain can develop in office workers who spend lots of time sitting, and forward movement of the body can increase the body's distortion significantly. Intercostal muscle stretching can improve the expired tidal volume, decrease dyspnea, and increase chest expansion, which results in better gas exchange clinically, 5). However, with intercostal pain caused by overstretching, further stretching may result in muscle weakness or even greater pain. Therefore, intercostal pain should be controlled through muscle strengthening. The backward lifting exercise expands the rib cage with thoracic extension and elevation of the scapula. It is believed that increasing the gap between the ribs increases the thoracic space. Finally, it provides proper muscle length for effective exercise. Therefore, backward lifting and thoracic extension is a good posture for activating the different layers of muscle that are attached to the ribs. The kyphosis angle is also reduced by providing sufficient resistance during the thoracic exercise.

\section{REFERENCES}

\footnotetext{
Neumann DA: Kinesiology of the musculoskeletal system: foundations for physical rehabilitation. St Louis: Mosby, 2009.

De Troyer A, Kirkwood PA, Wilson TA: Respiratory action of the intercostal muscles. Physiol Rev, 2005, 85: 717-756. [Medline] [CrossRef]

Gregory PL, Biswas AC, Batt ME: Musculoskeletal problems of the chest wall in athletes. Sports Med, 2002, 32: 235-250. [Medline] [CrossRef]

Stochkendahl MJ, Christensen HW: Chest pain in focal musculoskeletal disorders. Med Clin North Am, 2010, 94: 259-273. [Medline] [CrossRef]

Leelarungrayub D, Pothongsunun P, Yankai A, et al.: Acute clinical benefits of chest wall-stretching exercise on expired tidal volume, dyspnea and chest expansion in a patient with chronic obstructive pulmonary disease: a single case study. J Bodyw Mov Ther, 2009, 13: 338-343. [Medline] [CrossRef]
} 